\title{
Öğretmen Adaylarının Teknolojik Pedagojik Alan Bilgisi Öz Güvenlerinin Değişiminin İncelenmesi
}

\section{An Investigation on Change of Pre-Service Teachers' Self-Confidence in Technological Pedagogical Content Knowledge}

\author{
Elvan İNCE AKA \\ Gazi Üniversitesi, Matematik ve Fen Bilimleri Eğitimi Bölümü, Fen Bilgisi Ĕ̆itimi ABD, ANKARA \\ e-posta: elvanince@gazi.edu.tr \\ Alev DOĞAN \\ Gazi Üniversitesi, Matematik ve Fen Bilimleri Ĕgitimi Bölümü, Fen Bilgisi Ĕ̆itimi ABD, ANKARA \\ e-posta: alevd@gazi.edu.tr \\ Ayşe SERT ÇIBIK \\ Gazi Üniversitesi, Matematik ve Fen Bilimleri Eğitimi Bölümü, Fen Bilgisi Ĕ̆itimi ABD, ANKARA \\ e-posta: sertay@gazi.edu.tr
}

\begin{abstract}
Atıf: İnce Aka, E., Doğan, A., \& Sert Çıbık, A. (2018). Öğretmen Adaylarının Teknolojik Pedagojik Alan Bilgisi Öz Güvenlerinin Değiş̧iminin İncelenmesi. E-Kafkas Eğitim Araştırmaları Dergisi, 5(1), 1-9.
\end{abstract}

Gönderi Tarihi: 05-10-2017

Kabul Edilme Tarihi: 06-03-2018

DOI: $10.30900 /$ kafkasegt.341868

\section{$\ddot{O z}$ et}

$\mathrm{Bu}$ çalışmanın amacı fen bilgisi öğretmen adaylarının teknolojik pedagojik alan bilgisi öz güvenlerinin değişimini incelemektir. Çalıșma, 2015-2016 eğitim-öğretim yılında bir devlet üniversitesinin Fen Bilgisi Eğitimi Anabilim Dalı son sınıfında okuyan 35 ögretmen adayı ile 8 haftalık (16 saat) bir eğitim kapsamında gerçekleştirilmiştir. İlk aşamada adaylara çoklu öğrenme unsurlarıyla ilgili uygulama örnekleri tanıtılmış ve adaylar gruplar halinde çalıştırılmıştır. Daha sonra adaylardan fen bilimleri alanından seçilmiş bazı konularla ilgili çoklu öğrenme unsurlarıyla desteklenmiş sunum hazırlamaları ve sunmaları istenmiştir. Çalışma yarı deneme modellerinden tek gruplu ön test-son test araştırma desenine uygun olarak tasarlanmıştır. Çalışmada veri toplama aracı olarak Teknolojik Pedagojik Alan Bilgisi Öz Güven Ölçeği (TPABÖGÖ) kullanılmıştır. Çalışma sonucunda, öğretmen adaylarının hazırladıkları ve sundukları çoklu öğrenme unsurlarıyla desteklenmiş sunumlarının, adayların teknolojik pedagojik alan bilgisi öz güvenlerinin değişiminde ve özellikle teknolojik pedagojik alan bilgisi ile teknolojik pedagojik bilgilerinde olumlu yönde etkiye sahip olduğu tespit edilmiştir.

Anahtar Kelimeler: Teknolojik pedagojik alan bilgisi, öz güven, çoklu öğrenme unsurları, öğretmen adayları

\begin{abstract}
The purpose of this study is to determine the change in pre service science teachers' self-confidence in technological pedagogical content knowledge. This study was conducted with 35 senior pre service science teachers who are enrolled in Science education department in a public university in the context of 8-week (16 hours) training in 2015-2016 academic year. In the first phase, the pre service science teachers were introduced with sample implementations of multimedia factors. Then, the participants were asked to prepare and present a presentation on the topics selected from the field of science enhanced with multimedia as a group. The study was designed according to the quasi-experimental one-group pretest-posttest modeling. Technological Pedagogical Content Knowledge Self-Confidence Scale was used as the data collection tool. As a result of the study, it was retained that pre service science teachers' power point presentations supported with the multimedia factors has a positive effect on the change of their confidence and the presentations prepared by using the multimedia factors revealed positive changes in technological pedagogical content knowledge and technological pedagogical knowledge in terms of sub-dimensions.
\end{abstract}

Keywords: Technological pedagogical content knowledge, self-confidence, multimedia factors, pre service teachers 


\section{GíRiş}

Teknolojik yeniliklerin büyük bir hızla ilerlediği ve bilimsel bilginin katlanarak arttığı, fen ve teknolojinin etkilerinin yaşamımızın her alanında belirgin bir şekilde görüldüğü günümüz bilgi-teknoloji çağında, fen ve teknoloji eğitimi anahtar bir rol oynamaktadır (MEB, 2004). İlk kez 2004 yılında fen ve teknoloji adı altında değiştirilen ilköğretim fen müfredatında teknoloji sadece dersin içeriğinde kalmamış aynı zamanda çeşitli öğretim yöntemleriyle bütünleştirilmiştir (Sancar-Tokmak, Sürmeli ve Özgelen, 2014). Bu değişimle birlikte teknolojinin eğitime olan etkisi ile ilgili uygulamalara ağılık verilmesi önem arz etmektedir. $\mathrm{Bu}$ açıdan düşünüldüğünde çoklu ortam unsurlarının farklı öğrenme yöntemleriyle birleştirilmesi eğitim ortamlarında yapılabilecek uygulamalar arasında olduğu söylenebilir.

Bilgisayar-insan etkileşiminde oluşan çalışma tarzının değişimini simgeleyen çoklu ortam; veri ve bilgi aktarımında, yazı, grafik, ses, müzik animasyon, video vb. değişik türdeki ortamları bilgisayar ortamında birleştirerek kullanmaktır (Numanoğlu, 1993). Literatür incelendiğinde sınıf içi uygulamalarda kullanılan çoklu ortam unsurlarının öğrenmeyi kolaylaştırdığı (Aslan ve Doğdu, 1993), anlamlı öğrenmeyi sağladığı ve öğrenci başarısını arttırdığı vurgulanmaktadır (Balkı, 2008; Doğan ve Yılmaz, 2012). Teknolojinin eğitim ortamlarında kullanılmaya başlanması da öğretmenlerin yeterliliklerinin değişmesini zorunlu hale getirmiştir. Bu durum özellikle öğretim sürecinde uygun materyaller ve kaynaklar kullanabilme yeterliğinin göz önüne alınmasını gerekli kılabilir. Nitekim teknolojik araçların ve bilişim teknolojilerinin sınıf ortamlarında kullanılması gerekliliği müfredatta vurgulanmaktadır (MEB, 2008). Mishra ve Koehler (2006)'e göre bu yeterlik kavramı Teknolojik Pedagojik Alan Bilgisi (TPAB) olarak tanımlanmaktadır. TPAB, alan uzmanının alan bilgisinden, teknoloji uzmanının teknolojik bilgisinden ve bir öğretmende bulunan pedagojik bilgilerden farklı ve bu üç bileşenin önüne geçen bilgi türüdür. TPAB; öğretmenlerin etkili bir eğitim ve öğretim yapabilmeleri için pedagojik alan bilgilerine ek olarak eğitim teknolojilerini etkili ve verimli olarak sınıflarında uygulamaları, teknolojiyi öğretimleri ve konu alanı ile uygun olarak bütünleştirmeleridir (Timur ve Taşar, 2011). Pedagojik alan bilgisi (PAB) ise, pedagojik alan bilgisi, pedagoji ve alan bilgisi arasındaki bağı kurar (Shulman, 1986).

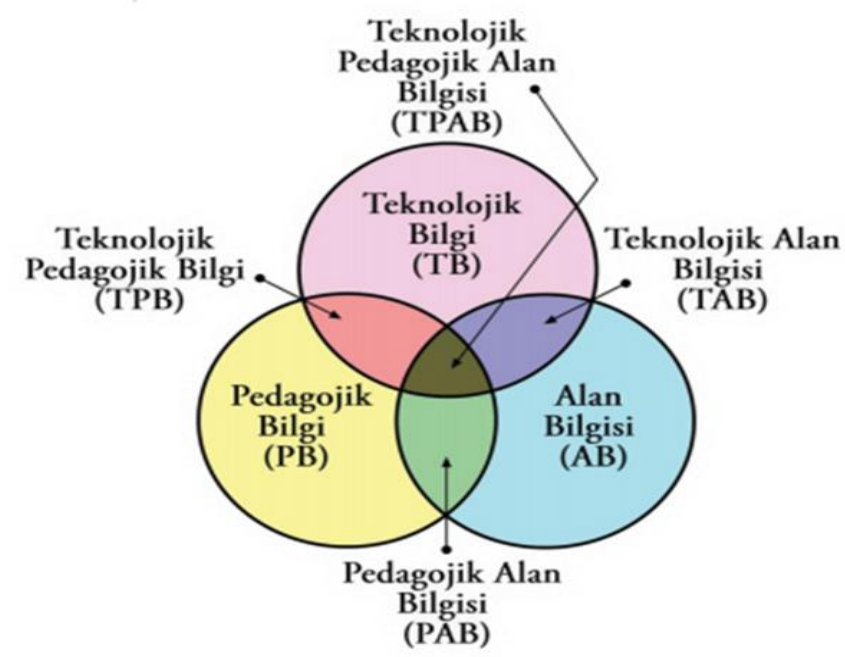

Şekil 1. Teknolojik pedagojik alan bilgisi (TPAB) kuramsal çerçevesi, (Mishra ve Koehler, 2006)

Şekil 1'de görüldüğü gibi TPAB, teknoloji, pedagoji ve alan bilgisinin birleştirilmesi ile yedi bilgi alanından oluşmaktadır. Bunlar; Teknoloji Bilgisi, Pedagoji Bilgisi, Alan Bilgisi, Pedagojik Alan Bilgisi, Teknolojik Alan Bilgisi, Teknolojik Pedagoji Bilgisi ve Teknolojik Pedagojik Alan Bilgisi’nden oluşmaktadır (Karakuyu ve Karakuyu, 2016). İçerik bilgisi, öğretilecek alan ile ilgili sahip olunan bilgileri ifade etmektedir (Harris, Mishra ve Koehler, 2007). Pedagoji bilgisi, öğretim ile ilgili süreç, uygulama ya da yöntemlerin bilgisini (Mishra ve Koehler, 2006); teknoloji bilgisi ise teknoloji okuryazarlığı, günlük hayatta teknoloji kullanımı ve teknolojik değişime uyum sağlama bilgisini içermektedir (Schmidt, Baran, Mishra, Koehler ve Shin, 2009). Bu bilgilerin etkili bir öğretim ile değişebilmesi için çoklu ortam unsurlarının sınıf içi uygulamalarda yer alması önemlidir. Nitekim öğrenme hedeflerinin başarılı bir biçimde gerçekleşebilmesi için çoklu ortam teknolojilerinden en az iki, ya da daha fazlasının kullanılması gerekmektedir (Çeliköz, 1998). Bu bağlamda 
çoklu ortam unsurlarıyla desteklenmiş sunumların (animasyon, simülasyon, vs.) öğretimde etkili ve verimli olması için öğretmenlerin bu bilgi ve beceri açısından donanımlı ve öz güvenlerinin de yüksek olması beklenmektedir.

Öz güven kavramı kısaca bireyin kendisini değerli hissetmesi yargısı (Bandura, 1977) olarak bilinmektedir. Feltz (1988) ise öz güveni "genel bir özellik olmaktan daha çok bireyin belli bir aktiviteyi başarılı biçimde yerine getireceğine yönelik inanc1 ve bireyin kendi yetenek, yargı, güç ve kararlarına güvenmesi" şeklinde tanımlamaktadır. Bireyler öğrenme ortamında kendilerine güven duyduklarında yüksek düzeyde öğrenmenin gerçekleşmesi sonucu kendilerini daha iyi hissederler. Kısacası öz güven duygusu yüksek olan bireyler günlük hayatta karşılaştıkları problemleri çözmede daha başarılıdır (Owens, 2001). Bu bilgiler doğrultusunda daha yaratıcı, başarıll, sorunlarla karşılaşmaktan ve üstesinden gelmekten korkmayan bireyler yetiştirmek bir öğretmen için önemlidir (Özevin Tokinan ve Bilen, 2011).

$\mathrm{Bu}$ nedenle, öğretmen adaylarının teknolojik pedagojik alan bilgisi öz güvenlerinin değişimini incelemek de onların teknolojiyi öğretim süreçleriyle etkili bir şekilde bütünleştirmelerini sağlamada önemli bir adımdır. Bu sebeple, öğretmen adaylarının sınıf içi uygulamalarda kullanacakları çoklu ortam unsurlarıyla desteklenmiş sunumlarının onların teknolojik pedagojik alan bilgisi öz güvenlerinin değişiminde olumlu etki yaratacağı söylenebilir.

\section{Araştırmanın Amacı}

$\mathrm{Bu}$ çalışmanın amacı öğretmen adaylarının hazırladıkları ve sundukları çoklu öğrenme unsurlarıyla desteklenmiş sunumlarının teknolojik pedagojik alan bilgisi öz güvenlerinin değişimine etkisini belirlemektir.

\section{Araştırmanın Problemi}

Araştırmanın amacı doğrultusunda aşağıdaki soruya cevap aranacaktır:

Çoklu öğrenme unsurlarıyla desteklenmiş sunumlarının teknolojik pedagojik alan bilgisi öz güvenlerinin değişimine etkisi nasıldır?

\section{YÖNTEM}

\section{Örneklem Grubu}

Çalışma, 2015-2016 eğitim-öğretim yılı bahar döneminde bir devlet üniversitesinin Fen Bilgisi Eğitimi Anabilim Dalı son sınıfında okuyan toplam 35 öğretmen adayı ile gerçekleştirilmiştir. Tanıdık bir örneklem üzerinde çalışmanın araştırmacılara pratiklik ve kolaylık sağlaması ve araştırmacıların diğer örnekleme yöntemlerini kullanma olanağının bulunmaması sebebiyle bu çalışmada kolay ulaşılabilir örnekleme yolu tercih edilmiştir (Yıldırım ve Şimşek, 2016).

\section{Araştırma Deseni ve Veri Toplama Aracı}

Çalışma yarı deneme modellerinden tek gruplu ön test-son test araştırma desenine uygun olarak tasarlanmıştır (Karasar, 1999). Çalışmada kullanılan ölçme aracı Graham, Burgoyne, Cantrell, Smith, Clair ve Harris (2009) tarafindan geliştirilen, Timur ve Taşar (2011) tarafindan Türkçe'ye uyarlanan Teknolojik Pedagojik Alan Bilgisi Öz Güven Ölçeğidir (TPABÖGÖ). Ölçek 6'lı likert tipinde olup 31 maddeden oluşmaktadır. Ayrıca ölçek, Teknolojik Pedagojik Alan Bilgisi (TPAB) boyutu, Teknolojik Pedagojik Bilgi (TPB) boyutu, Teknolojik Alan Bilgisi (TAB) ve Teknolojik Bilgi (TB) boyutu olmak üzere 4 alt boyutu içermektedir.

Ölçekte 1=Hiç güvenmiyorum, 2=Az güveniyorum, $3=$ Orta derece güveniyorum, $4=$ Çokça güveniyorum $5=$ Tamamen güveniyorum ve 5 madde için (16-20. maddeler) $0=\mathrm{Bu}$ türden teknolojileri bilmiyorum şeklinde sıralanmıştır. Ölçekten alınabilecek en yüksek puan 186 ve en düşük puan ise 26 'dır. Timur ve Taşar (2011) tarafindan ölçeğin geneli için Cronbach Alpha güvenirlik katsayısı .92, TPAB boyutu için .89, TPB boyutu için .87 , TAB bilgisi boyutu için .89 ve TB boyutu için .86 olarak bulunmuştur.

\section{Uygulama Süreci}

Uygulama 2015-2016 eğitim-öğretim yılı bahar döneminde bir devlet üniversitesinin Fen Bilgisi Eğitimi Anabilim Dalında, Teknoloji ve Proje Tasarımı dersinde gerçekleştirilmiştir. Uygulama üç aşamadan oluşmaktadır. Birinci aşamada, adaylara 4 haftalık bir süreçte çoklu ortam unsurlarıyla ilgili uygulama örnekleri tanıtılmıştır. Sonrasında bireyleri öğrenmeye aktif olarak katmak, iletişimi geliştirmek ve en önemlisi bilgi transferini kolaylaştırmak amacıyla öğretmen adaylarının uygulama sürecinde gruplar halinde çalışması 
sağlanmıştır. Grup çalışmalarında, sunum içeriklerinde kullanacakları videolar, animasyonlar, simülasyonlar, fotoğraflar, resimler üzerine çeşitli genel uygulamalar yapılmıştır. İkinci aşamada ( 2 hafta) ise adaylardan fen bilimleri dersi kapsamında belirledikleri ünitelerle (vücudumuzdaki sistemler, insanda üreme, büyüme ve gelişme, kuvvet ve enerji, ışık ve ses, maddenin yapısı ve özellikleri vb) ilgili kazanımlar çerçevesinde çoklu öğrenme unsurlarıyla (animasyonlar ve simülasyonlar) desteklenmiş power point sunumlarını hazırlamaları istenmiştir. Ders kapsamı dışında da adaylar yaptıkları çalışmaları araştırmacılarla paylaşarak dönütler almışlardır. Son aşamada (2 hafta) ise adaylar aldıkları dönütler ve bilgi paylaşımları neticesinde hazırladıkları sunumları sınıfta diğer gruplara sunmuşlardır. Ayrıca, gruplar sunumlar hakkında süreçte öğrendiklerini tartışmışlardır. Uygulama toplamda 8 hafta (16 saat) sürmüştür. Sürecin değerlendirilmesinde, Teknolojik Pedagojik Alan Bilgisi Öz Güven Ölçeği (TPABÖGÖ) ön-test ve son-test olarak kullanılmıştır.

\section{Verilerin Analizi}

Verilerin analizinde SPSS 18.00 programı kullanılmış ve adaylara uygulanan ön-test ve son-test arasında anlamlı farklılık olup olmadığını belirlemek amacıyla da bağımlı (ilişkili) gruplar t-testi uygulanmıştır. (Büyüköztürk, 2007).

\section{BULGULAR ve YORUMLAR}

Fen bilgisi öğretmen adaylarının çoklu öğrenme unsurlarıyla desteklenmiş sunumlarının teknolojik pedagojik alan bilgisi öz güven değişimlerine olan etkisinin belirlendiği bu araştırmada analiz sonucunda elde edilen bulgular tablolarda verilmiş ve ölçek alt boyutları bakımından da değerlendirilmiştir. Tablo 1'de TPABÖGÖ puanlarının ön-test/son-test betimsel istatistik değerleri ile uygulama öncesi ve sonrası puanları arasındaki farklılık gösterilmiştir.

Tablo 1.

ТРАВӦGÖ puanlarının ön-test/son-test betimsel istatistik değerleri ve bă̆ımlı gruplar t-testi sonuçları

\begin{tabular}{|c|c|c|c|c|c|c|c|c|c|}
\hline \multirow[b]{2}{*}{$\begin{array}{c}\text { Bağımlı } \\
\text { değişken }\end{array}$} & \multicolumn{3}{|c|}{ Ön test } & \multicolumn{3}{|c|}{ Son test } & \multirow[b]{2}{*}{$\mathbf{t}$} & \multirow[b]{2}{*}{ df } & \multirow[b]{2}{*}{$\mathbf{p}$} \\
\hline & $\mathbf{N}$ & $\bar{X}$ & SS & $\mathbf{N}$ & $\bar{X}$ & SS & & & \\
\hline TPABÖ & 35 & 116.43 & 17.41 & 35 & 125.80 & 15.23 & -2.39 & 68 & $.019 *$ \\
\hline
\end{tabular}

$* \mathrm{p}<.05$

Tablo 1 incelendiğinde, adayların TPABÖGÖ ön-test ve son-test puanları arasında istatistiksel olarak anlamlı bir farklılık olduğu görülmektedir $\left[\mathrm{t}_{(35)}=-2.396, \mathrm{p}<.05\right]$. Bu durum, çoklu öğrenme unsurlarıyla desteklenmiş sunumlarının adayların öz güven düzeylerinin değişiminde olumlu yönde etkiye sahip olduğunu göstermektedir. Bu bulguya göre öğretmen adaylarının çoklu öğrenme unsurlarıyla destekli sunum hazırlama süreçleri ve bu etkinlikleri sınıf ortamında uygulamalarıyla kendilerine olan güvenlerin arttığı söylenebilir. Tablo 2 'de TPABÖGÖ puanlarının alt boyutlara göre ön-test/son-test betimsel istatistik değerleri ile uygulama öncesi ve sonrası puanları arasındaki farklılık gösterilmiştir.

Tablo 2.

TPABÖGÖ puanlarının alt boyutlara göre ön test-son test betimsel istatistik değerleri ve bağıml gruplar t-testi sonuçlart

\begin{tabular}{lccccccccc}
\hline Alt boyutlar & \multicolumn{3}{c}{ Ön test } & \multicolumn{6}{c}{ Son test } \\
& N & $\bar{X}$ & sd & $\mathbf{N}$ & $\bar{X}$ & sd & $\mathbf{t}$ & $\mathbf{d f}$ & $\mathbf{p}$ \\
\hline TPAB & 35 & 29.54 & 4.48 & 35 & 32.80 & 4.64 & -2.98 & & $.004^{*}$ \\
TPB & 35 & 26.83 & 4.97 & 35 & 29.49 & 3.82 & -2.50 & 68 & $.015^{*}$ \\
TAB & 35 & 18.06 & 4.27 & 35 & 19.43 & 3.87 & -1.40 & & .164 \\
TB & 35 & 42.00 & 6.60 & 35 & 44.09 & 6.47 & -1.33 & & .186 \\
\hline
\end{tabular}

$* \mathrm{p}<.05$

Tablo 2 incelendiğinde de adayların uygulanan ölçeğin ön-test ve son-test puanlarında teknolojik pedagojik alan bilgisi ve teknolojik pedagojik bilgi alt boyutlarında istatistiksel olarak anlamlı bir farklılık 
olduğu görülmektedir. Sonuç itibariyle gerçekleştirilen uygulamaların adayların TPAB ve TPB alt boyutları açısından öz güven değiş̧imlerinde olumlu yönde katkı sağladığı söylenebilir.

\section{TARTIŞMA}

Öğretmen adayları, öğretmenlik mesleklerine başlamadan önce yükseköğrenimleri sırasında programlarında yer alan bazı derslerde mesleğe hazırlık olarak çeşitli sunumlar yapmaktadır. Bu çalışmada da adayların bu durumlarına katkı sağlamak ve bu anlamda onlara temel beceriler kazandırmak amaçlanmış ve bu doğrultuda fen bilgisi öğretmen adaylarının çoklu öğrenme unsurlarıyla desteklenmiş sunumlarını içeren 3 aşamadan oluşan bir uygulama ile teknolojik pedagojik alan bilgisi öz güvenlerinin değişimi incelenmiştir.

Eğitim teknolojilerinin hızla geliştiği günümüzde power point, video, akıllı tahta, animasyon, simülasyon, ses, müzik, grafik....gibi çoklu öğrenme unsurları her geçen gün ilk öğrenimden yüksek öğrenime kadar her alanda kullanılmaktadır. Genel olarak, bu unsurların kullanımı öğrencilerin akıl yürütme ve karar verme gibi üst düzey düşünme becerilerini geliştirmede ve araştırma becerilerini pekiştirmede de oldukça önemli bir rol oynar (Rakes, Fields ve Cox, 2006; Efe, 2011; Öztürk, 2013). Ayrıca, bu tür teknolojilerin kullanımı daha zengin öğrenme ortamları oluşturduklarından öğrencilerin motivasyonlarının artmasını da sağlamaktadır. Fen bilimleri öğretmenlerinin de özellikle öğrenme hedeflerini başarılı bir biçimde gerçekleşebilmesi ve eğitimöğretim faaliyetlerinde etkili sonuçlar alabilmesi için çağın gerektirdiği teknolojik unsurları sınıf ortamlarında verimli şekilde kullanabilmeleri de son derece önemlidir (Çeliköz, 1998; Numanoğlu, 1993).

Araştırmamızda adaylar özellikle sunumlarında animasyon ve simülasyon kullanmaya özen göstermişlerdir. Animasyon kullanımının bilimsel gerçek, olgu, kavram ve prensiplerin öğretiminde etkili olduğu (Jacobson ve Kozma, 2000), konuların görsel ve işitsel olarak işlenerek öğrencilerin üç boyutlu düşünmelerini sağladığı (Arıcı ve Dalkılıç, 2006), böylelikle öğrencilerin bilimsel bilgileri yorumlayabilmelerine ve bilişsel yeteneklerinin gelişimine yardımcı olduğu bilinmektedir (Yang, Andre ve Greenbowe, 2003). Benzer şekilde adaylar tarafından sunumlarında kullanılan simülasyonlar da özellikle fen alanlarında anlaşılması zor olan soyut kavramları somutlaştırması, yapılması zor ya da mümkün olmayan deneylerin kolaylıkla yapılması ve anlaşılmasını sağlaması açısından öğrenmeyi kolaylaştırmaktadır (Pektaş, Çelik, Katrancı ve Köse, 2009).

Öğretmen adaylarıyla yapılan bu uygulamalar ve elde edilen bulgular doğrultusunda adayların çoklu öğrenme unsurlarıyla desteklenmiş power point sunumlarının genel olarak onların öz güvenlerinin değişiminde olumlu etkisi olmuştur (Tablo 1-2). Araştırmanın bulgularından elde edilen verilere göre; öğretmen adaylarının teknolojik pedagojik alan bilgisi öz güven ölçeğinin alt boyutlarından TPAB ve TPB öz güven düzeylerinin anlamlı bir şekilde artığı, TAB ve TB boyutlarındaki öz güven düzeylerinde anlamlı bir değişimin olmadığı tespit edilmiştir.

TPAB, fen dersinde interneti ve dijital teknolojileri kullanarak fen dersinde kavram yanılgılarını bulmayı, bu konuda veri toplamayı ve araştırma yapmayı içeren ifadeleri kapsamaktadır. TPB ise dijital teknolojilerle öğretim yaparken sınıf yönetimini sağlamayı, iletişimi etkili kullanma yönünde öz güven ifadelerini içermektedir (Mishra ve Koehler, 2006). Buna göre, öğretmen adaylarının sunumlarını hazırlarken her aşamada fen bilimleri kapsamında araştırdıkları konuyla ilgili gerek alan bilgisi, gerekse alana özgü pedagojik yöntem bilgisini yeterli derecede özümsedikleri ve tüm bunları uygularken teknolojik bilgilerini de iyi yönde kullandıkları söylenebilir.

Teknoloji bilgisini (TB) Mishra ve Koehler (2006) "kitap, tebeşir, tahta gibi standart teknoloji hakkında bilgiler ve internet, dijital video gibi daha gelişmiş teknolojiler hakkındaki bilgiler" olarak tanımlamışlardır. Teknolojik alan bilgisi (TAB) ise teknoloji ve alan bilgilerinin hem birbirini etkilediği hem de kısıtladığı bir bilgi türü olarak tanımlanmıştır (Mishra ve Koehler, 2006; Harris, Mishra ve Koehler, 2009). Yani bir yandan teknolojik materyallerin derslerde kullanılmasıyla öğretmenin ders sunum biçimi kısıtlanırken diğer yandan daha yeni teknolojiler geliştikçe derste teknoloji kullanımı öğretmene ders sunum esnekliği kazandırır (Mishra ve Koehler, 2006). Birbiriyle ters orantılı görünen bu ilişki (Mishra ve Koehler, 2006) sebebiyle adayların, süreç boyunca teknolojik bilgi ve teknolojik alan bilgilerini yeteri kadar yapılandıramadıkları ve dolayısıyla TB öz güvenlerinin değişimini sınırladığı söylenebilir.

Konuyla ilgili benzer olarak yapılan araştırmalarda da öğretmen adaylarına verilen teknoloji destekli eğitimin, gerçek bir öğrenme ortamında uygulanmadıkça adayların kendilerine tam olarak güvenemedikleri (Suharwoto ve Niess, 2001) belirlenmiş̧ir. Dolayısıyla teknolojik bilgisini iyi şekilde yapılandırmış bir ögretmenin kendine daha fazla güvenebileceği ve bu bilgisini diğer bilgi yapılarıyla daha hızlı entegre edebileceği de söylenebilir. Nitekim Canbolat (2011)'ın yaptığı bir çalışmada teknolojiyi sınıf ortamında ders içeriği ile entegre ederek kullanan öğretmenlerin öz güvenlerinin yüksek olduğu tespit edilmiştir. Konuyla ilgili 
olarak literatürde araştırma sonuçlarımızı destekler nitelikte çalışmalara ulaşmak mümkündür (Sancar-Tokmak ve Yanpar-Yelken, 2015; Tatlı, Akbulut ve Altınışık, 2016). Tatlı ve diğerleri (2016)'nin Web 2.0 araçlarının eğitim amaçlı kullanımı etkinliği kapsamında yaptıkları çalışmada, öğretmen adaylarının TPAB öz güven düzeylerinde anlamlı bir artış bulunmuştur. Benzer şekilde Sancar-Tokmak ve Yanpar-Yelken (2015)'in dijital hikâye oluşturmaya yönelik yaptıkları deneysel çalışmada öğretmen adaylarının TPACK öz güven puanları arasında anlamlı farklılık olduğu tespit edilmiştir.

Sonuç itibariyle sınıf içi ortamlarda öğrenci ile uyarıcıyı direkt etkileşim durumuna getiren çoklu öğrenme unsurlarının öğretim sırasında kullanılmasının faydalı olduğu ve TPAB gelişimine olumlu katkılar sağlayacağı bir gerçektir. Fen eğitiminin amacına ulaşmasında öğretim faaliyetlerinde oldukça önemi olan çoklu ortam unsurlarının, sınıf içi uygulamalarda öğretmenler tarafından müfredata entegre edilerek, doğru bir şekilde kullanılması da ayrıca önemlidir.

\section{KAYNAKÇA}

Arıcı, N. \& Dalkılıç, E. (2006). Animasyonların bilgisayar destekli öğretime katkısı. Kastamonu Eğitim Dergisi, 14 (2), 421 430.

Aslan, Z. \& Doğdu, S. (1993). Eğitim teknolojisi uygulamalart ve eğitim araç gereçleri. Ankara: Tekışık Ofset.

Balkı, E. (2008). Öğretmenlerin bilişim teknolojilerine ilişskin alglları ve uygulamalarl: Özel Konya Esentepe ilköğretim okulu örneği. Yayımlanmamış Yüksek Lisans Tezi. Selçuk Üniversitesi, Konya.

Bandura, A. (1977). Self-efficacy: Toward an unifying theory of behavioral change. Psychological Review, 84 (2), 191-215.

Büyüköztürk, Ş. (2007). Sosyal bilimler için veri analizi el kitabı. 7. Baskı, Ankara: Pegem A Yayıncılık.

Canbolat, N. (2011). Matematik öğretmen adaylarının teknolojik pedagojik alan bilgileri ile düşünme stilleri arasındaki ilişkinin incelenmesi. Yayımlanmamış Yüksek Lisans Tezi. Selçuk Üniversitesi Eğitim Bilimleri Enstitüsü Ortaögretim Fen ve Matematik Alanları Eğitimi Anabilim Dalı Matematik Eğitimi Bilim Dalı, Konya.

Çeliköz, N. (1998). Eğitimde çoklu ortam (Multimedia). Eğitim ve Bilim, 22 (108), 3-8.

Doğan, Y. \& Yılmaz, M. (2012). Fen ve teknoloji dersinde öğretim teknolojilerinin kullanımının incelenmesi. Adiyaman Üniversitesi Fen Bilimleri Dergisi, 2 (2), 107-121.

Efe, R. (2011). Science student teachers and educational technology: Experience, intentions, and value. Educational Technology \& Society, 14 (1), 228-240.

Feltz, D. L. (1988). Self-confidence and sports performance. Exercise and Sports Science Reviews, 16 (1), 423-458.

Graham, C. R., Burgoyne, N., Cantrell, P., Smith, L., St. Clair, L. \& Harris, R. (2009). TPACK development in science teaching: Measuring the TPACK confidence of inservice science teachers. TechTrends, Special Issue on TPACK, 53 (5), 70-79. doi: 10.1007/s11528-009-0328-0

Harris, J. B., Mishra, P. \& Koehler, M. J. (2007). Teachers' technological pedagogical content knowledge: Curriculumbased technology integration reframed. Annual Meeting of the American Educational Research Association, Chicago, IL.

Harris, J. B., Mishra, P. \& Koehler, M. J. (2009). Teachers' technological pedagogical content knowledge and learning activity types: Curriculum-based technology integration reframed. Journal of Research on Technology in Education, 41 (4), 393-416.

Jacobson, M. J. \& Kozma, R. B. (2000). Innovations in science and mathematics education. Advanced designs for technologies of learning, New Jersey, London: Lawrence Erlbaum Associates, Publishers.

Karakuyu, Y. \& Karakuyu, A. (2016). Motivasyon ve öz-yeterliğin sınıf öğretmeni adaylarının teknolojik pedagojik alan bilgilerine (TPAB) katkısı. Uşak Üniversitesi Eğitim Araşstrmaları Dergisi, 2 (1), 89-100.

Karasar, N. (1999). Bilimsel araşstrma yöntemi. Ankara: Nobel Yayınları.

MEB (2004). Illkögretim fen ve teknoloji dersi ögretim programı. Ankara: Devlet Kitapları Müdürlüğü.

MEB (2008). Fen ve teknoloji öğretmeni özel alan yeterlikleri. Ankara: Milli Eğitim Bakanlığı öğretmen Yetiştirme ve Eğitimi Genel Müdürlüğ̈̈ Web: http://otmg.meb.gov.tr/YetOzel.html. (14.10.2016).

Mishra, P. \& Koehler, M. J. (2006). Technological pedagogical content knowledge: A framework for teacher knowledge. The Teachers College Record, 108 (6), 1017-1054.

Numanoğlu, M. (1993). Eğitimde yeni teknolojiler ve çoklu ortam. Ankara Üniversitesi Eğitim Bilimleri Fakültesi Dergisi, 26 (1), 219-226. doi: 10.1501/Egifak_0000000508

Owens, T. J. (2001). Extending self-esteem theory and research. Cambridge: University Press.

Özevin Tokinan, B. \& Bilen, S. (2011). The effects of creative dancing activities on motivation, self-esteem, self-efficacy and dancing performance. Hacettepe University Journal of Education, 40 (40), 363-374.

Öztürk, E. (2013). Sınıf öğretmeni adaylarının teknolojik pedagojik alan bilgilerinin bazı değişkenler açısından değerlendirilmesi. Uşak Üniversitesi Sosyal Bilimler Dergisi, 6 (2), 223-238. doi: 10.12780/UUSBD163 
Pektaş, H. M., Çelik, H., Katrancı, M. \& Köse, S. (2009). 5. sınıflarda ses ve 1şı ünitesinin öğretiminde BDÖ’nün öğrenci başarısına etkisi. Kastamonu Eğitim Fakültesi Dergisi, 17 (2), 657-667.

Rakes, G. C., Fields, V. S. \& Cox, K. E. (2006). The influence of teachers' technology use on instructional practices. Journal of Research on Technology in Education, 38 (4), 411-426. doi: 10.1080/15391523

Sancar-Tokmak, H. \& Yanpar-Yelken, T. (2015). Effects of creating digital stories on foreign language education pre-service teachers' TPACK self-confidence. Educational Studies, 41 (4), 444-461.

Sancar-Tokmak, H., Sürmeli, H. \& Özgelen, S. (2014). Pre-service science teachers' perceptions of their TPACK development after creating digital stories. International Journal of Environmental and Science Education, 9 (3), 247-264.

Schmidt, D. A., Baran, E., Thompson, A. D., Mishra, P., Koehler, M. J. \& Shin, T. S. (2009). Technological Pedagogical Content Knowledge (TPACK): The development and validation of an assessment instrument for preservice teachers. Journal of Research on Technology in Education, 42 (2), 123-149. doi: 10.1080/15391523.

Shulman, L. (1986). Those who understand: Knowledge growth in teaching. Educational Researcher, 15 (2), 4-14.

Suharwoto, G. \& Niess, M. (2001). How do subject specific teacher preparation program that integrate technology throughout the courses support the development of mathematics preservice teachers' TPCK. Web: http://eusesconsortium.org/docs/Site_With_Gogot.pdf (02.10. 2017).

Tatlı, Z., Akbulut, H. İ. \& Altınışı, D. (2016). Öğretmen adaylarının Teknolojik Pedagojik Alan Bilgisi özgüvenlerine Web 2.0 araçlarının etkisi. Turkish Journal of Computer and Mathematics Education, 7 (3), 659-678.

Timur, B. \& Taşar, M. F. (2011). Teknolojik pedagojik alan bilgisi öz güven ölçeğinin (TPABÖGÖ) Türkçe'ye uyarlanması. Gaziantep Üniversitesi Sosyal Bilimler Dergisi, 10 (2), 839-856.

Yang, E., Andre, T. \& Greenbowe, T. J. (2003). Spatial ability and the impact of visualization animation on learning electrochemistry. International Journal of Science Education, 25 (3), 329-349.

Yıldırım, A. \& Şimşek, H. (2016). Sosyal bilimlerde nitel araştırma yöntemleri. Ankara: Seçkin. 


\title{
An Investigation on Change of Pre-Service Teachers' Self-Confidence in Technological Pedagogical Content Knowledge
}

\author{
Elvan İNCE AKA \\ Gazi University, Turkey \\ e-posta: elvanince@gazi.edu.tr \\ Alev DOĞAN \\ Gazi University, Turkey \\ e-posta: alevd@gazi.edu.tr \\ Ayşe SERT ÇIBIK \\ Gazi University, Turkey \\ e-posta: sertay@gazi.edu.tr
}

Citation: İnce Aka, E., Doğan, A., \& Sert Çıbık, A. (2018). An Investigation on Change of Pre-Service Teachers' SelfConfidence in Technological Pedagogical Content Knowledge. E-Kafkas Journal of Educational Research, 5(1), 1-9.

\section{Extended Summary}

Introduction: Science and Technology education has a key role in today's information and technology era in which technological innovations have been growing rapidly, scientific knowledge has been increasing incrementally and the effects of science and technology is seen prominently. Technology in the science curriculum, which was changed into science and technology in 2004 is not only related to the context but also is integrated with the teaching methods and presentation elements. Along with this change, while emphasizing the effect of technology on education, the first thing that comes to mind are the multimedia factors. Multimedia compounds different types of medias such as writing, graphic, sound, music, animation and video in electronic environment during the data and knowledge transfer. For this reason, the purpose of this study is to determine the effect of power point presentations which have been supported by multimedia factors on the pre service science teachers' self-confidence in technological pedagogical content knowledge. In accordance with this main purpose, this study was conducted in Technology and Project Design course in the Department of Science teaching of a state university during the spring term of the 2015-2016 educational period.

Method: The study was conducted with 35 pre service teachers in their senior year in the Department of Science Teaching of a state university during the spring term of the 2015-2016 educational period. Easily available sample type has been selected during the selection of the samples. The study has been designed according to the pretest-posttest modeling. Technological Pedagogical Content Knowledge Self-Confidence Scale has been used in order to identify the pre service teachers' technological pedagogical content knowledge confidence. In 6-likert scale, the items have been numbered as $1=\mathrm{I}$ never trust, $2=\mathrm{I}$ hardly trust $3=\mathrm{I}$ reasonably trust, $4=\mathrm{I}$ greatly trust, $5=\mathrm{I}$ completely trust and $0=\mathrm{I}$ don't know such Technologies. The scale is composed of 31 items and 4 sub dimensions. In this scale, the maximum score that can be reached is 186 and the minimum score is 26 . Findings about the construct validity of the scale have been ensured through the factor analysis method. Cronbach Alpha coefficient has been measured as .92 while it has been measured as .89 for TPCK, .87 for TPK, .89 for TCK and $.86 \mathrm{TK}$ dimension. There is no negative item in this scale. The application comprises three stages. In the first stage, the application about the multimedia factors have been introduced to the candidates for about 4 weeks. In the second stage, the candidates have been asked to prepare a power point presentation supported with the multimedia factors in the frame of skills of the units that they have defined in the context of sciences previously. The last stage is the one during which the candidates present their presentations. Pre service teachers have studied in groups during the application process. The application have taken 8 weeks in total.

Findings, Discussion and Recommendations: In the study, quasi-experimental one-group pretest-posttest modeling has been used. SPSS programme has been used in the analysis of the data and the other descriptive analyses have been conducted by using the mode, median and arithmetic mean from the descriptive statistics. On the other hand, dependent samples t-test analysis has been used in order to determine whether the application is effective or not. According to the findings of the study, it has been confirmed that pre service science teachers' power point presentations supported with the multimedia factors has a positive effect on the change of their TPCK confidence.

To sum up, it has been determined that the use of multimedia factors that make a direct interaction between the students and the stimulant is helpful during the education process and it has provided the pre service teacher 
with the positive technological, pedagogical contribution and also with the contribution in the development of content knowledge. For this reason, it is important for the teachers in the university to prepare presentations by using multimedia factors and to gain main skills through their usage. Moreover, it is possible to develop the teachers' knowledge and skills through the on-the-job seminars in order for the extension of the usage of the multimedia factors and for their application in other fields and contents. 